\title{
RABA (Reductive Alkylation By Acetone): A Novel Stable Isotope Labeling Approach for Quantitative Proteomics
}

\author{
Jianjun Zhai, Xiaoyan Liu, Zhenyu Huang, and Haining Zhu \\ Department of Molecular and Cellular Biochemistry, College of Medicine, University of Kentucky, Lexington, \\ Kentucky, USA
}

\begin{abstract}
Quantitative proteomics is challenging and various stable isotope based approaches have been developed to meet the challenge. Hereby we describe a simple, efficient, reliable, and inexpensive method named reductive alkylation by acetone (RABA) to introduce stable isotopes to peptides for quantitative analysis. The RABA method leads to alkylation of N-terminal and lysine amino groups with isopropyl moiety. Using unlabeled $\left(\mathrm{d}_{0}\right)$ and deuterium labeled $\left(\mathrm{d}_{6}\right)$ acetone, a 6 Da mass split is introduced to each isopropyl modification between the light and heavy isotope labeled peptides, which is ideally suited for quantitative analysis. The reaction specificity, stoichiometry, labeling efficiency, and linear range of the RABA method have been thoroughly evaluated in this study using standard peptides, tryptic digest of proteins, as well as human cell lysate. Reliable quantitative results have been consistently obtained in all experiments. We also applied the RABA method to quantitative analysis of proteins in spinal cords of transgenic mouse models of amyotrophic lateral sclerosis. Highly homologous proteins (transgenic human SOD1 and endogenous mouse SOD1) were distinguished and quantified using the method developed in this study. In addition, the quantitative results using the RABA approach were independently validated by Western blot. (J Am Soc Mass Spectrom 2009, 20, 1366-1377) () 2009 American Society for Mass Spectrometry
\end{abstract}

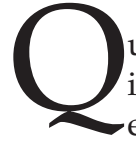

uantitative analysis of protein expression levels is a critical issue in proteomics. Mass spectrometry (MS) has become one of the most powerful tools in proteomic analysis in the past decade [1]. Several MS-based methods have been developed for quantitative proteomics analysis [2-6]. In particular, stable isotope labeling approaches that generate pairs of light and heavy isotopic peaks with several Da mass difference have been widely used. These methods are based on the generation of two pools of protein/ peptide samples-one with naturally occurring isotopes (light) and the other with enriched heavy isotopes such as deuterium ${ }^{2} \mathrm{D},{ }^{13} \mathrm{C},{ }^{15} \mathrm{~N}$ or ${ }^{18} \mathrm{O}$. Equal quantities of these two samples are pooled and subjected to the same preparation and analysis procedures. The light and heavy isotopic peaks are resolved in mass spectrometry and their relative abundances are calculated to represent the relative quantification of the corresponding protein in the starting samples.

Stable isotopes can be incorporated into proteins either in vivo during cell growth or in vitro after cell lysis. The examples of in vivo labeling include universal ${ }^{15} \mathrm{~N}$ labeling $[4,7-9]$ and amino acid specific labeling [5, $10-13]$. However, these methods are limited to cultured

Address reprint requests to Dr. H. Zhu, Department of Molecular and Cellular Biochemistry, College of Medicine, University of Kentucky, 741 South Limestone, Lexington, KY 40536, USA. E-mail: haining@uky.edu cells and cannot be extended to studying animal or patient tissues. The in vitro stable isotope labeling approaches introduce various isotopic tags through chemical reactions with proteins/peptides and usually target specific amino acid residues such as cysteine and lysine, N-terminal or C-terminal residues of tryptic peptides [14-23]. An elegant example is the design of an isotope-coded affinity tag (ICAT) that contains a thiol-reactive group that reacts with cysteine residues, a polyether linker that can be labeled with deuterium, and an affinity tag, e.g. biotin, that allows the rapid purification of the cysteine-containing peptides [3]. However, the ICAT approach cannot analyze peptides lacking a cysteine residue. Acylation of $\mathrm{N}$-terminus and $\varepsilon$-amino groups of lysine residues by acetic anhydride or N-acetoxysuccinimide has also been reported [2426]. However, acylation of basic amine groups changes the ionic states of peptides and may reduce the ionization efficiency of peptides. Alternatively, ${ }^{18} \mathrm{O}$ can be introduced to the C-terminus of tryptic peptides during protein hydrolysis by trypsin [27, 28]. More recently, iTRAQ reagents, a new family of isobaric multiplex tagging derivates, have been introduced for 4-plex [29-33] and 8-plex [34, 35] quantitative proteomic analysis. The iTRAQ reagents are amine-specific and react with $\mathrm{N}$-terminus and lysine residues of the trypsin digested peptides. A particular peptide from up to four samples yields the same mass value after being modi- 
fied with a group of 4-plex iTRAQ reagents. However, the modified peptide yields four different reporter ions in the MS/MS mode, representing the relative abundances of this peptide in the four starting samples.

We here describe a simple and cost-effective method using acetone to modify amine groups at both $\mathrm{N}$ terminus and lysine residues based on a well established reductive alkylation reaction [36, 37]. The reductive alkylation by acetone (RABA) reaction can be utilized to modify peptides stoichiometrically with over $99 \%$ yield in 30 min with high specificity toward primary amine groups. Using unlabeled ( $\mathrm{d}_{0}$-acetone) and deuterium labeled acetone $\left(\mathrm{d}_{6}\right.$-acetone), this method introduces $6 \mathrm{Da}$ mass split for each isopropyl modification between the light and heavy isotope labeled peptides, which can avoid the naturally occurring isotope envelops and thus is ideally suited for quantitative analysis. The application of this reaction to quantitative analysis is demonstrated and evaluated using standard peptides, tryptic peptides from proteins as well as human cell lysate and transgenic mouse tissue homogenate in this study. The results support that the RABA method can be used to achieve reliable quantification of proteins levels in complex samples. The advantages of the RABA approach include the ready availability of the inexpensive reagents, the relative simplicity of the reaction, and the high yield to produce labeled peptides in 2 hours.

\section{Experimental}

\section{Materials}

Acetone, acetone- $\mathrm{d}_{6}$ (cat no. 540331, 99.9 atom \% deuterium), sodium cyanoborohydride $\left(\mathrm{NaBH}_{3} \mathrm{CN}\right)$, dithiothreitol (DTT), iodoacetamide (IAA), formic acid, trifluoroacetic acid (TFA), angiotensin II, horse cytochrome $c$, horse myoglobin, bovine serum albumin (BSA), and $\alpha$-cyano-4-hydroxycinnamic acid (CHCA) were purchased from Sigma-Aldrich (St. Louis, MO). Trypsin was obtained from Promega (Madison, WI). HPLC grade acetonitrile and water were obtained from Fisher Scientific (Hampton, NJ). Strong cation exchange bead (POROS 20 HS) was from Applied Biosystems (Foster City, CA).

\section{Cell Culture and Animal Methods}

Human embryonic kidney cell line (HEK293) was cultured at $37{ }^{\circ} \mathrm{C}$ under $5 \% \mathrm{CO}_{2}-95 \%$ air in Dulbecco's modified Eagle's medium (DMEM, Gibco) containing $10 \%$ fetal bovine serum, 100 units $/ \mathrm{mL}$ penicillin, and $100 \mu \mathrm{g} / \mathrm{mL}$ streptomycin. Cells were harvested after reaching $90 \%$ confluence. Cell lysate was prepared as previously described [38] and served as a complex background in testing the quantitative approach in this study.

Transgenic mice strains overexpressing WT and G93A mutant SOD1, which are the animal models for studying amyotrophic lateral sclerosis (ALS, Lou Gehrig's disease), were maintained as hemizygotes at the University of Kentucky animal facility. G93A SOD1 transgenic mice and age-matched WT SOD1 transgenic mice were sacrificed at age of $90 \mathrm{~d}$. Mice were anesthetized with an intraperitoneal injection of $0.3 \mathrm{~mL}$ of pentobarbital $(50 \mathrm{mg} / \mathrm{mL}$; Abbott Laboratories, Abbott Park, IL) and transcardically perfused with $0.1 \mathrm{M}$ PBS, $\mathrm{pH}$ 7.5. Spinal cords were dissected as previously described [39] and subjected to quantitative analysis using the approach developed in this study. All animal procedures were approved by each university's IACUC committee.

\section{RABA Reaction of Peptides}

Standard proteins, BSA, myoglobin, and cytochrome $c$, were dissolved in $25 \mathrm{mM} \mathrm{NH} \mathrm{NCO}_{3}$ and digested overnight at $37^{\circ} \mathrm{C}$ with trypsin without performing DTT reduction. The stock solutions of the tryptic peptides of BSA, myoglobin and cytochrome $c$ were at concentrations of $13.4,49.0$, and $55.6 \mathrm{pmol} / \mu \mathrm{L}$, respectively, based on the amount of proteins used for digestion.

Peptides, both standard peptide (angiotensin II) and tryptic peptides of proteins, were dissolved in $90 \%$ acetonitrile containing $0.1 \%$ formic acid at indicated concentrations. The reducing reagent $\mathrm{NaBH}_{3} \mathrm{CN}$ was freshly prepared before use each time in unlabeled $\left(\mathrm{d}_{0}\right.$-acetone) or deuterated acetone $\left(\mathrm{d}_{6}\right.$-acetone) at the concentration of $36 \mu \mathrm{g} / \mu \mathrm{L}$. The RABA reaction was performed by mixing $20 \mu \mathrm{L}$ peptide solution and $5 \mu \mathrm{L}$ acetone containing $36 \mu \mathrm{g} / \mu \mathrm{L} \mathrm{NaBH}_{3} \mathrm{CN}$ at roomtemperature for $30 \mathrm{~min}$ or indicated periods of time. The reaction mixture was dried using a SpeedVac (Thermo, Holbrook, NY) and the reaction stopped after acetone evaporated. The sample was reconstituted in $20 \mu \mathrm{L} \mathrm{90 \%}$ acetonitrile containing $0.1 \%$ formic acid and subjected to mass spectrometric analysis. The mock reaction control was carried out in the same fashion except using acetone without the reducing reagent $\mathrm{NaBH}_{3} \mathrm{CN}$, in which the RABA reaction did not occur.

Different periods of reaction time were tested and the reaction yield over the time course of the RABA reaction was determined. Different quantities of peptides were used as starting material in the RABA reaction to evaluate the sensitivity of the reaction.

\section{Quantitative Analysis Using RABA Reaction with Peptides}

Peptides were reacted with unlabeled $\left(\mathrm{d}_{0}\right.$-acetone) or deuterated acetone $\left(\mathrm{d}_{6}\right.$-acetone $)$ separately, subsequently mixed, and subjected to mass spectrometric analysis. Different quantities of peptides were used in each reaction and the ratio of the quantities of peptides used in the $d_{0}$ - and $d_{6}$-acetone $R A B A$ reaction was defined as the expected ratio. The experimental ratio was calculated based on the ratio of the centroid intensities of the 
light and heavy isotopic peaks of the peptide (which were derived from $d_{0}$ - and $d_{6}$-acetone, respectively). In the direct infusion experiments, MS spectra were obtained by averaging the spectra acquired over one minute and the centroid intensities of the light and heavy isotopic peaks in the average MS spectra were used for calculating ratios. In the nano-LC-MS/MS experiments, MS spectra were averaged over peak elution of each peptide of interest.

The dynamic range of the method was first tested by quantifying angiotensin II mixed at various expected ratios $\left(\mathrm{d}_{0}: \mathrm{d}_{6}\right.$ from 1:20 to 20:1). Furthermore, myoglobin, cytochrome $c$ and BSA tryptic digestion samples were mixed with various expected ratios. The ratios of the proteins were experimentally determined by subjecting the tryptic peptides to the $d_{0^{-}}$or $d_{6}$-acetone RABA reaction, mixing the two reaction samples, analyzing the reaction mixture by mass spectrometry, and calculating the ratio of the light and heavy isotopic peaks of the $\mathrm{d}_{0}$ - and $\mathrm{d}_{6}$-isopropyl products. The experimentally measured ratios were compared to the expected ratios of the protein mixtures to demonstrate the accuracy of this approach.

\section{RABA Reaction of Tryptic Peptides in the Background of Human Cell Lysate}

We then tested whether this approach is able to distinguish protein abundance changes in the background of complex mixture. More complex samples were prepared by spiking standard proteins to the HEK293 cell lysate. Sample A contained $120 \mu \mathrm{g}$ HEK293 cell lysate and a total of $2 \mu \mathrm{g}$ of BSA, myoglobin and cytochrome c $(0.8 \mu \mathrm{g}$ BSA, $0.6 \mu \mathrm{g}$ myoglobin and $0.6 \mu \mathrm{g}$ cytochrome c). Samples B, C, and D contained $120 \mu \mathrm{g}$ HEK293 cell lysate and 2, 4, and $10 \mu \mathrm{g}$ of BSA, myoglobin and cytochrome $c$, respectively. All samples were subjected to dithiothreitol (DTT) reduction, iodoacetamide (IAA) alkylation, and trypsin digestion in solution over night. Three pairs of comparison samples were generated using the above tryptic peptides: B:A, C:A, and D:A. Each pair of samples was subjected to RABA reaction using $\mathrm{d}_{0}$ - and $\mathrm{d}_{6}$ - acetone for $2 \mathrm{~h}$ at room temperature as described earlier. The reaction was quenched by adding $10 \mu \mathrm{L} 1 \mathrm{M}$ glycine (final concentration of $0.25 \mathrm{M}$ ). Equal amount of $\mathrm{d}_{0^{-}}$and $\mathrm{d}_{6}$-modified peptides were mixed and subjected to nano-LC-MS/MS analysis as described below. The ratios of BSA, myoglobin and cytochrome $c$ in the three pairs of samples were determined by calculating the ratio of the light and heavy isotopic peaks of the $\mathrm{d}_{0}$ - and $\mathrm{d}_{6}$-isopropyl products over the peak elution of the corresponding peptide. The experimentally measured ratios were compared to the expected ratios of the protein mixtures to demonstrate the accuracy of this approach in the complex background of human cell lysate.

\section{RABA Reaction of Tryptic Peptides Derived from Transgenic Mouse Tissues}

Dissected mouse spinal cords were lysed in radioimmune precipitation assay (RIPA) buffer (50 mM Tris$\mathrm{HCl} \mathrm{pH} 7.4,1 \%$ Nonidet P- $40,0.25 \%$ sodium deoxycholate, $150 \mathrm{mM} \mathrm{NaCl}, 1 \mathrm{mM}$ EDTA) as previously described [39]. Protein concentrations were determined by Bradford assay (BioRad, Hercules, CA) and equal amount of protein from wild type and mutant SOD1 mice spinal cord was precipitated by trichloroacetic acid (TCA). The proteins were re-dissolved in $25 \mathrm{mM}$ ammonia bicarbonate containing $0.2 \%$ SDS, then subjected to DTT reduction, IAA alkylation, and trypsin in-solution digestion over night. The resulting tryptic peptides from wild-type and G93A mouse spinal cords were labeled by RABA reaction with $\mathrm{d}_{0}$ - and $\mathrm{d}_{6}$-acetone, respectively. The RABA reaction was quenched by $1 \mathrm{M}$ glycine after $2 \mathrm{~h}$ reaction at room-temperature. The equal amount of $\mathrm{d}_{0^{-}}$and $\mathrm{d}_{6}$-isopropyl modified peptides were mixed and then fractionated by strong cation exchange beads using step gradient containing $50 \%$ $\mathrm{ACN}, 0.1 \%$ formic acid, and varying concentrations of ammonium acetate from 0 to $200 \mathrm{mM}$. A total of 9 fractions (unbound supernatant, and fractions eluted with $0,20,40,60,80,100,150,200 \mathrm{mM}$ ammonium acetate) were collected. Each fraction was concentrated from 200 to $\sim 20 \mu \mathrm{L}$, and $5 \mu \mathrm{L}$ of each fraction were subjected to reverse phase LC-MS/MS analysis.

The LC-MS/MS data were submitted to a local MASCOT server for MS/MS protein identification search using "merged search" function of Mascot Daemon. The MS/MS data from nine ion-exchange fractions were combined to perform a single merged search. The typical parameters were: Mammal for standard proteins, Homo sapiens for HEK293 cell lysate, and Mus for mouse spinal cord homogenate, Sprot database (51.0), maximum of three trypsin missed cleavages, cysteine carbamidomethylation, methionine oxidation, $\mathrm{d}_{0}$-isopropyl, $\mathrm{d}_{6}$-isopropyl, $100 \mathrm{ppm}$ MS error tolerance, and 0.5 Da MS/MS error tolerance. The search was mainly utilized to identify the $\mathrm{d}_{0^{-}}$or $\mathrm{d}_{6}$-isopropyl modified peptides in this study. The ratio of the intensities of the light and heavy isotopic peaks of each tryptic peptide was calculated over the peak elution of the corresponding peptide. The ratios of several tryptic peptides from the same protein were averaged as the experimentally determined quantitative results of the protein.

\section{Mass Spectrometry}

The reductive alkylation reaction products were analyzed by both electrospray (ESI) MS/MS and MALDITOF-TOF mass spectrometry. The ESI MS/MS data were collected from a Q-Star XL quadrupole time-offlight mass spectrometer (ABI/MDS SCIEX, Foster City, CA) using either direct infusion or a nano-flow HPLC system (Eksigent, Dublin, CA). For direct infusion 
ESI-MS analysis, the sample was diluted $10 \times$ with $90 \%$ acetonitrile containing $0.1 \%$ formic acid and loaded to $\mathrm{Au} / \mathrm{Pd}$-coated spray emitter (Proxeon, Odense, Denmark). The electrospray voltage was $2100 \mathrm{~V}$ and the mass range of TOF MS was from 350 to $1600(\mathrm{~m} / \mathrm{z})$. Nano-flow LC-MS/MS was done by exploiting the nano-HPLC system for sample pick-up and separation, where desired volume of sample solution was injected by autosampler and desalted on a trap column (LC Packings $300 \mu \mathrm{m}$ i.d. $\times 5 \mathrm{~mm}$ ), and was subsequently separated by reverse phase C18 column (Vydac $75 \mu \mathrm{m}$ i.d. $\times 150 \mathrm{~mm}$ ) at a flow rate of $200 \mathrm{~nL} / \mathrm{min}$. The HPLC gradient was linear from 5 to $75 \% \mathrm{~B}$ in 55 min using mobile phase $\mathrm{A}\left(\mathrm{H}_{2} \mathrm{O}, 0.1 \%\right.$ formic acid $)$ and $\mathrm{B}(80 \%$ acetonitrile, $0.1 \%$ formic acid). Data acquisition was done using information-dependent mode, each cycle typically consisted of a 1s TOF MS survey from 350 to $1600(\mathrm{~m} / \mathrm{z})$ and two 2s MS/MS scans with mass range of 100-1600 (m/z).

MALDI-TOF-TOF mass spectrometry was performed using a 4800 Plus analyzer (ABI/MDS SCIEX, Foster City, CA) equipped with a $355 \mathrm{~nm} \mathrm{N_{2 }}$ laser (200 $\mathrm{Hz}$ ). Matrix was prepared by dissolving CHCA in $50 \%$ acetonitrile, $0.1 \%$ TFA at a concentration of $1 \mu \mathrm{g} / \mu \mathrm{L}$. Samples were diluted $20 \times$ before spotting, mixed with the matrix 1:1 and air-dried. The MALDI-TOF spectra were acquired with 400 laser shots.

\section{Western Blotting}

Selected proteins in the mouse spinal cord experiment were subjected to Western blotting analysis for independent confirmation of the quantitative results obtained by the RABA approach. Briefly, 15-25 $\mu \mathrm{g}$ of wild type and G93A mice spinal cord protein were subjected to $15 \%$ SDS-PAGE gels and transferred onto nitrocellulose membranes. Membranes were blocked in 5\% milk or 3\% BSA in TBST (100 mM Tris-buffered saline, $\mathrm{pH}$ $7.4,0.15 \%$ Tween-20) for $1 \mathrm{~h}$ at room temperature, followed by incubation with the indicated primary antibodies in TBST for $5 \mathrm{~h}$ at room temperature. After three washes with TBST membranes were incubated with the indicated secondary antibodies for $1 \mathrm{~h}$ at room temperature. After washing membranes for three times with TBST, the protein of interest was visualized using Super West Pico Enhanced Chemiluminescent (ECL) substrate or Supersignal West Dura extended duration ECL substrate kit (Pierce, Rockford, IL). Intensities of western blotting bands were quantified using the Kodak 1D software (version 3.6.1, Kodak, Rochester, NY).

\section{Results and Discussion}

\section{RABA Reaction with Peptides}

Reductive alkylation is a classical organic reaction that involves the conversion of a carbonyl group to an amine $[36,37]$. In this study, we explored to use the readily available solvent acetone as the reagent to react with peptides, which we name as RABA (reductive alkylation by acetone) reaction. The RABA reaction yields the addition of an isopropyl group to the N-terminus of a peptide and the $\varepsilon$-amino group of Lys residues (see eq 1), producing a $42 \mathrm{Da}$ mass increase for each isopropyl addition to peptides. Moreover, when deuteriumenriched acetone $\left(d_{6}\right.$-acetone) is used in the reaction, a mass increase of $48 \mathrm{Da}$ will be produced for each $\mathrm{d}_{6}$-isopropyl group attached to peptides. The 6 Da mass split between the $\mathrm{d}_{0}$ - and $\mathrm{d}_{6}$-isopropyl modified peptides can minimize the contribution of the naturally occurring isotopic envelop to a negligible level, providing an advantage over smaller mass split introduced by other labeling methods [18, 20, 23]. Therefore, the RABA approach would provide the benefit of significantly less interference from naturally occurring isotopic peaks.

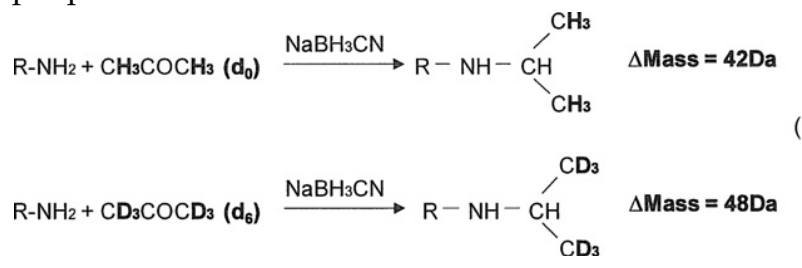

Figure 1 shows the ESI (Figure 1a) and MALDI-TOF (Figure 1b) mass spectra of a standard peptide angiotensin II with and without the RABA reaction. The top panel is angiotensin II in the control using acetone without the reducing regent $\mathrm{NaBH}_{3} \mathrm{CN}$, in which the RABA reaction did not occur. A peak at $m / z 523.76$ in the ESI mass spectrum represents the doubly charged ions of angiotensin II and a peak at $\mathrm{m} / \mathrm{z} 534.76$ represents the doubly charged ion of sodium adducts of angiotensin II (top panel). After 30 min RABA reaction as described in the Experimental section, a peak at $\mathrm{m} / \mathrm{z}$ 544.80 represents the doubly charged ion of angiotensin II with one isopropyl group at the N-terminus (middle panel). Similarly, the sodium adduct of the angiotensin II-isopropyl product was detected at $m / z$ 555.79. We did not detect any di-isopropyl products of angiotensin II, suggesting that the RABA reaction only produces mono-isopropyl product to the amine group of the peptide. The data also demonstrate that the arginine residue in the peptide does not react with acetone. The results confirmed the findings of Fretheim et al. although they used sodium borohydride in the alkylation of peptide with acetone [36].

The ESI mass spectrum of equal quantity of angiotensin II with and without the RABA reaction is shown in the lower panel of Figure 1a. The intensity of the isopropylmodified angiotensin II was $\sim 1$.7-fold stronger compared to that of the unmodified peptide. The isopropyl group introduced by the RABA reaction increases the basicity of the peptide, thus improving the ionization efficiency of the peptide as previously reported [14, 15]. However, the pair of $\mathrm{d}_{0^{-}}$and $\mathrm{d}_{6}$-isopropyl modified peptides showed no ionization efficiency difference in this study (see Figure 3c). 


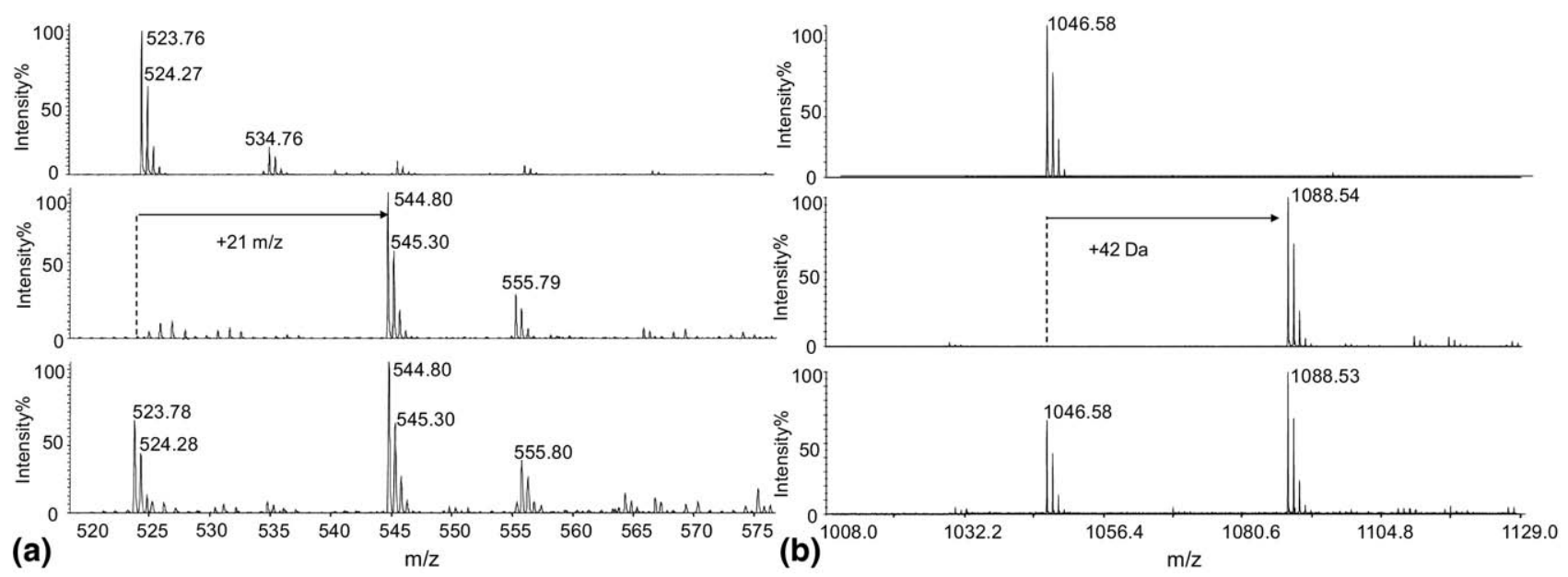

Figure 1. The electrospray (a) and MALDI-TOF (b) mass spectra of angiotensin II with and without the RABA reaction. The top panels are the spectra of un-modified angiotensin II that underwent the mock reaction without the reducing agents. The middle panels show the spectra of angiotensin II after 30 min RABA reaction. The lower panels show the spectra of equal volume mix of angiotensin II in the top and middle panels. In the ESI mass spectra in Figure 1a, both protonated $(\mathrm{m} / \mathrm{z} 523.76)$ and Na-adduct (544.80) of angiotensin II were detected. The unmodified angiotensin II was not detected in ESI and MALDI-TOF spectra after $30 \mathrm{~min}$ RABA reaction. The ionization efficiency of the isopropyl-modified peptide is higher than the intact peptide in both ESI and MALDI-TOF spectra.

We also performed MALDI-TOF analysis of angiotensin II with and without the RABA reaction and the spectra are shown in Figure 1b. Consistent with the ESI data, the reaction between angiotensin II and acetone produces a mono-isopropyl product of angiotensin II. In addition, the isopropyl-modified angiotensin II also yielded $\sim 1.6$-fold stronger signals than the unmodified angiotensin II.

\section{Time Course of the RABA Reaction with Peptides}

We observed that the RABA reaction with peptides went extremely fast, particularly under the acidic conditions in our experiments. We used the intensities of the isopropyl product and the native angiotensin II peaks to calculate the yield of the RABA reaction at different intervals of reaction time as defined by eq 2 . The cofactor $\mathrm{f}$ reflects the different ionization efficiencies of intact and isopropyl-modified angiotensin II. Based on the ESI spectrum in Figure $1 \mathrm{a}$, the $\mathrm{f}$ cofactor is 1.7 for angiotensin II.

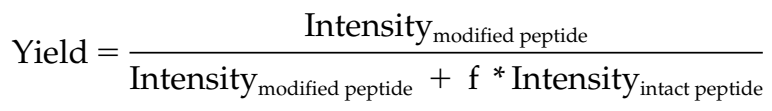

The reaction yield of the RABA reaction with angiotensin II was $93.3 \%$ after 3 min reaction, $96 \%$ after $10 \mathrm{~min}$, and reached $\sim 99 \%$ in $30 \mathrm{~min}$. Therefore, all RABA reactions with peptides were performed for $30 \mathrm{~min}$ in further experiments unless indicated otherwise.

\section{Sensitivity of the RABA Reaction with Peptides}

Since the quantities of proteins/peptides in proteomics studies may be limited, we tested how much peptide was required to perform a complete RABA reaction. When 1.0 pmol myoglobin tryptic peptide was used as the starting material for the RABA reaction, the concentration of the peptides in the $25 \mu \mathrm{L}$ reaction mixture was $40 \mathrm{fmol} / \mu \mathrm{L}$. The reaction was performed for $30 \mathrm{~min}$ and stopped by vacuum drying. The sample was reconstituted in $20 \mu \mathrm{L}$ water $/ 0.1 \%$ formic acid and one fourth of the sample (i.e., $5 \mu \mathrm{L}$ aliquot containing $250 \mathrm{fmol}$ myoglobin tryptic peptides) was subjected to LCMS/MS analysis and MASCOT search for isopropylmodified peptides. Eleven tryptic peptides were identified (67\% sequence coverage) and all of them were isopropyl-modified. We further tested the RABA reaction using $200 \mathrm{fmol}$ myoglobin tryptic peptides as starting material, i.e., $8 \mathrm{fmol} / \mu \mathrm{L}$ tryptic peptides in 25 $\mu \mathrm{L}$ reaction mixture. One-fourth of the reaction mixture (i.e., $50 \mathrm{fmol}$ myoglobin tryptic peptides) was subjected to LC-MS/MS analysis and we detected five isopropylmodified tryptic peptides (33\% sequence coverage). In addition, the un-modified tryptic peptides were still not observed in the extraction ion chromatograph in both experiments. The results demonstrate that the RABA reaction with peptides can be achieved stoichiometrically even at the low fmol/ $\mu \mathrm{L}$ peptide concentration.

\section{Quantitative Analysis Using Peptide RABA Reaction: Dynamic Range and Reproducibility in Reverse Labeling}

After establishing the specificity, time course and sensitivity of the RABA reaction using acetone, we used d6-acetone in the RABA reaction in the same fashion as described above. We observed identical specificity, time course, and sensitivity of the reaction using d6-acetone. It is critical to the success of a stable isotope labeling 

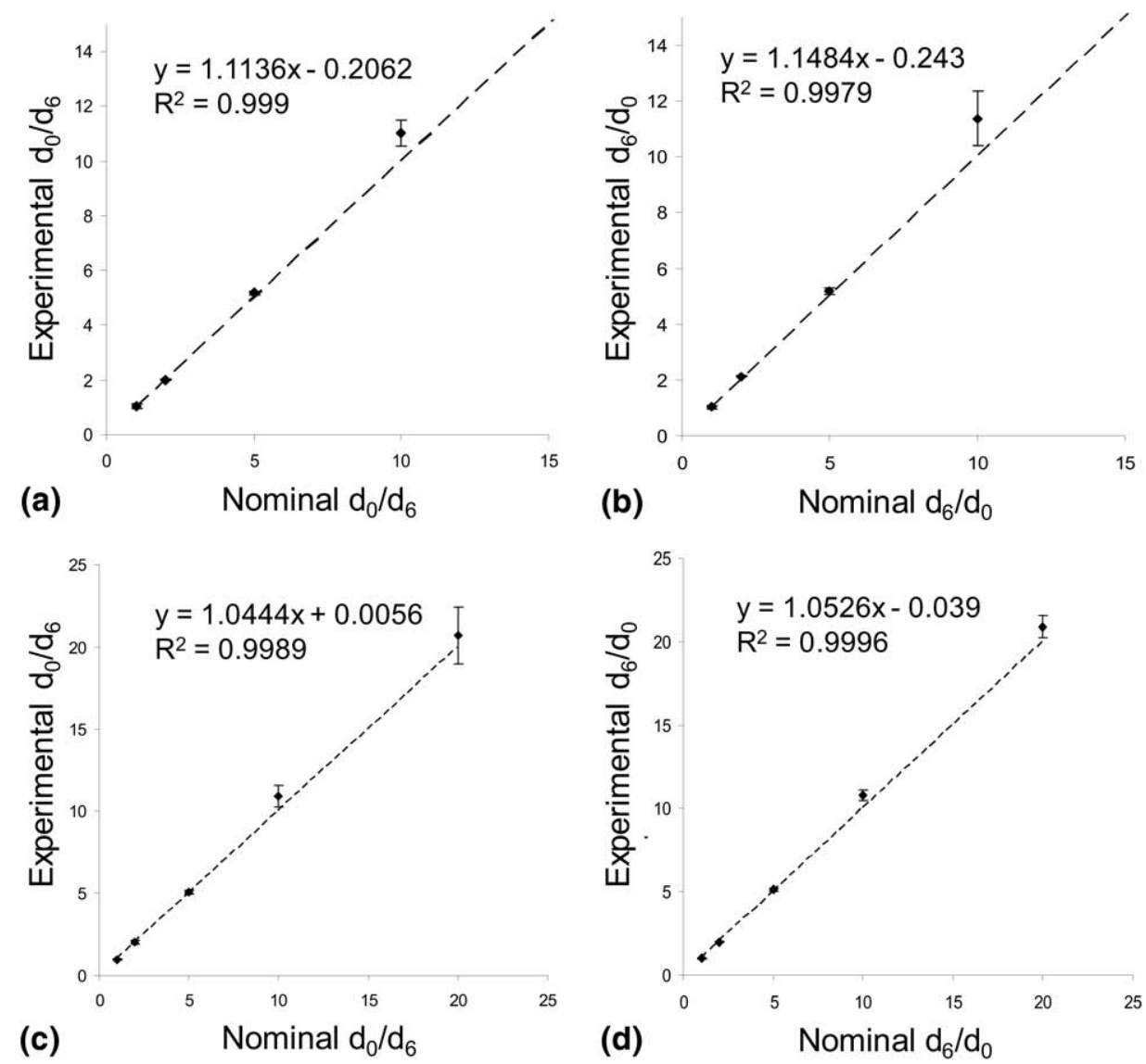

Figure 2. The linear range of the quantitative approach using the RABA reaction with peptides. The experimentally determined ratios are plotted versus expected ratios. Figure $3 a$ and $b$ are experimental ratios determined using ESI mass spectrometry. Figure 3a and $\mathrm{d}$ are experimental ratios determined using MALDI-TOF mass spectrometry. The forward and reverse labeling of peptide $\left(\mathrm{d}_{0} / \mathrm{d}_{6}\right.$ and $\left.\mathrm{d}_{6} / \mathrm{d}_{0}\right)$ were carried out to demonstrate that the RABA approach has little isotope scrambling. The linear regression of the experimental ratios is shown in each panel. The dashed lines are expected lines of the expected ratios.

technique to minimize the back-exchange and scrambling of the incorporated stable isotopes. In the RABA reaction with angiotensin II using d6-acetone, the dominant peak in the mass spectrum is the $D_{6}$-isopropyl modified peptide, along with a minor peak representing $\mathrm{D}_{5} \mathrm{H}_{1}$-isopropyl modified peptide (spectrum shown in Supplementary Figure 1 in the supporting materials, which can be found in the electronic version of this article). As shown in the figure, the intensity of the $\mathrm{D}_{5} \mathrm{H}_{1}$ peak is $\sim 1 \%$ of that of the $\mathrm{D}_{6}$-isopropyl modified peptide. A possible explanation for the $\mathrm{D}_{5} \mathrm{H}_{1}$-isopropyl modified peptide is that a small portion of the enol isomer of d6-acetone may undergo deuterium to hydrogen back exchange in solution. In addition, the d6acetone used in this study was 99.9 atom\% of deuterium, which also helped minimizing the peak of the $\mathrm{D}_{5} \mathrm{H}_{1}$-isopropyl modified peptide. Given the low abundance of the $\mathrm{D}_{5} \mathrm{H}_{1}$-isopropyl modified peptide, the isotope effect in the RABA reaction using d6-acetone is negligible. Thus, this reaction is suitable for incorporating stable isotopes to peptides and being utilized for quantitative analysis.
We first evaluated the dynamic range of the RABAbased quantitative analysis. Angiotensin II was diluted from $50 \mathrm{pmol} / \mu \mathrm{L}$ stock solution (in $90 \%$ acetonitrile, $0.1 \%$ formic acid) to 25,10 and $5 \mathrm{pmol} / \mu \mathrm{L}$. RABA reaction with $20 \mu \mathrm{L}$ of $50 \mathrm{pmol} / \mu \mathrm{L}$ angiotensin II solution was performed using $\mathrm{d}_{0}$-acetone. RABA reaction with each $20 \mu \mathrm{L}$ of $50,25,10$ and $5 \mathrm{pmol} / \mu \mathrm{L}$ angiotensin II solutions was performed using d6acetone. Equal volume of the $\mathrm{d}_{0}-$ and $\mathrm{d}_{6}$-RABA reaction was mixed to generate samples with expected ratios of $\mathrm{d}_{0} / \mathrm{d}_{6}=1: 1,2: 1,5: 1$ and 10:1, respectively. Similarly, different quantities of $\mathrm{d}_{0^{-}}$and $\mathrm{d}_{6}$-isopropyl modified angiotensin II were mixed at reverse ratios at $\mathrm{d}_{6} / \mathrm{d}_{0}=$ $1: 1,2: 1,5: 1$, and 10:1, respectively. The samples of the $\mathrm{d}_{0}$ - and $\mathrm{d}_{6}$-isopropyl modified angiotensin II were analyzed by direct infusion ESI-MS. The experimental ratio of $\mathrm{d}_{0^{-}}$and $\mathrm{d}_{6}$-isopropyl adducts in each sample was calculated using the intensities of the light and heavy monoisotopic peaks. All experiments were carried out in triplicates independently.

Figure 2a shows the experimentally determined $d_{0} / d_{6}$ ratios versus the expected ratios. Figure $2 b$ shows 

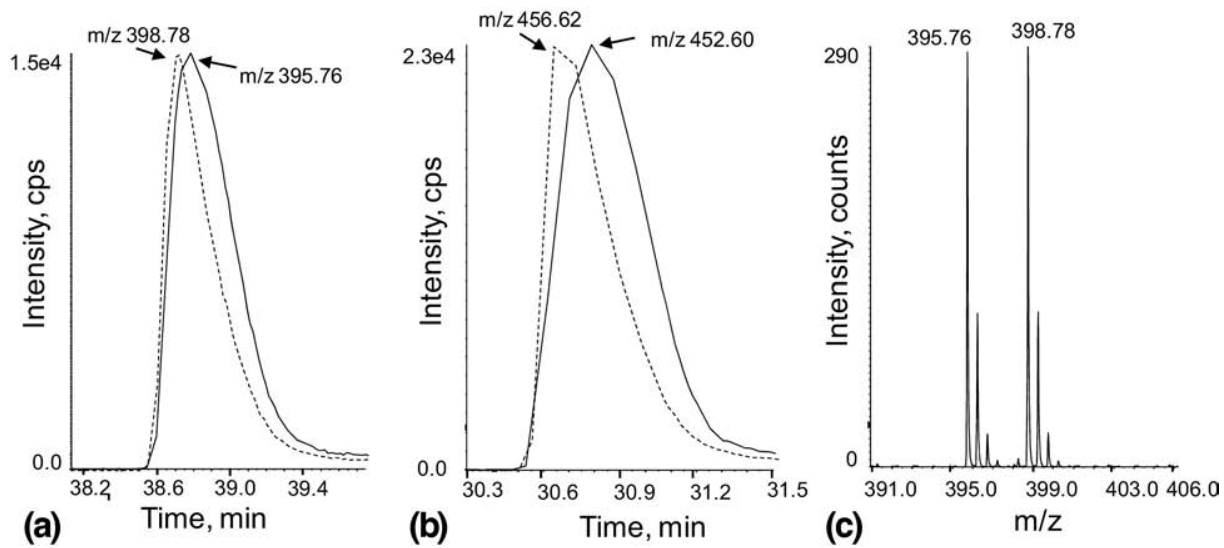

Figure 3. The LC-MS/MS spectra of light and heavy isotope labeled myoglobin tryptic peptides. (a) The extracted ion chromatography (XIC) of $\mathrm{m} / \mathrm{z} 395.76$ (solid line) and $\mathrm{m} / \mathrm{z} 398.78$ (dashed line) corresponding to the doubly charged ions of $\mathrm{d}_{0}$-and $\mathrm{d}_{6}$-isopropyl modified peptide ALELFR. The pair of the light and heavy isotope labeled peptides largely co-eluted with the heavy isotope labeled peptide eluting $\sim 2 \mathrm{~s}$ earlier. (b) The XIC of $\mathrm{m} / \mathrm{z} 452.60$ (solid line) and $\mathrm{m} / \mathrm{z} 456.62$ (dashed line) peaks corresponding to the triply charged ions of $\mathrm{d}_{0}$ - and $\mathrm{d}_{12}$-di-isopropyl modified peptide LFTGHPETLEK. The heavy isotope labeled peptide eluted $\sim 8 \mathrm{~s}$ earlier. (c) The average mass spectrum across the elution time of the pair of $\mathrm{d}_{0}$ - and $\mathrm{d}_{6}$-isopropyl modified peptide ALELFR shown in (a).

the experimentally determined $\mathrm{d}_{6} / \mathrm{d}_{0}$ ratios versus the expected ratios. The experimental ratios clearly agree with the expected ratio in the dynamic range from 1:10 to 10:1. Within this range, the correlation coefficiency $\left(R^{2}\right)$ is 0.999 and 0.998 for Figure $2 a$ and b, respectively. The relative standard deviation (RSD) of the triplicate experiments is less than $10 \%$ for all data points. Thus, the quantitative results using RABA reaction can be faithfully reproducible in reverse labeling, which provides strong support for the reliability and accuracy of this stable isotope labeling strategy.

Furthermore, we performed the dynamic range studies of the quantitative analysis of the above mixtures using a different type of mass spectrometer, MALDITOF. As shown in Figure $2 \mathrm{c}$ and $\mathrm{d}$, the ratios determined by the peak intensities from the MALDI-TOF mass spectra consistently agree with the expected ratios. The dynamic range obtained from the MALDI-TOF data is from 1:20 to 20:1, which is even better than that obtained from direct infusion ESI-MS. Within this range, the correlation coefficiency $\left(R^{2}\right)$ is 0.999 for both Figure $2 \mathrm{c}$ and $\mathrm{d}$. The relative standard deviation (RSD) of the triplicate experiments is less than $10 \%$ for all data points. The results again demonstrate that the RABA reaction can produce reliable quantitative analysis in both directions of stable isotope labeling. In addition, this strategy can be used for both ESI and MALDI types of mass spectrometers.

It is noted that the RABA reaction was independently carried out for each individual sample of different quantities of peptides and the $d_{0}$-acetone and $d_{6}$ acetone reaction samples were subsequently mixed. This experimental design, instead of simply mixing the same reaction products at different ratios, more closely resembles practical applications in which different quantities of proteins/peptides need to react with the reagents individually before mixing. Thus, the results presented in this study are more likely to be achieved in practical applications. It is also noted that the peptides were analyzed by direct infusion nano-ESI mass spectrometry without HPLC enrichment in this set of experiments. The pmol $/ \mu \mathrm{L}$ concentrations used in the experiments are equivalent to typical practical applications in which femtomole quantities of peptides are analyzed by nano-LC-MS/MS.

\section{Quantitative Analysis Using Peptide RABA Reaction: Application to Tryptic Peptides}

After testing the technique with a single peptide angiotensin II, we performed the RABA reaction with the tryptic peptides of myoglobin. Different quantities myoglobin tryptic peptides in the range of $500 \mathrm{fmol}$ to 10 pmol were subjected to the RABA reaction using $d_{0}-$ and $\mathrm{d}_{6}$-acetone, respectively. The $\mathrm{d}_{0}$ - and $\mathrm{d}_{6}$-isopropyl modified peptides were mixed and an aliquot of 200 fmol reaction mixture was subjected to nano-LCMS/MS analysis. Figure 3 shows representative nanoLC-MS/MS results of the $\mathrm{d}_{0}$ - and $\mathrm{d}_{6}$-isopropyl modified myoglobin tryptic peptides. Figure $3 \mathrm{a}$ is the extracted ion chromatography (XIC) of $m / z 395.76$ (solid line) and $\mathrm{m} / \mathrm{z} 398.78$ (dashed line) peaks that represent the doubly charged ions of mono $\mathrm{d}_{0}-$ and $\mathrm{d}_{6}$-isopropyl modified peptide ALELFR. This pair of mono-isopropyl modified peptides, which are $6 \mathrm{Da}$ mass units apart, largely co-eluted in the reverse phase HPLC with a slight separation of retention time of $\sim 2 \mathrm{~s}$. Figure $3 \mathrm{~b}$ shows the XIC of $m / z 452.60$ (solid line) and $\mathrm{m} / \mathrm{z} 456.62$ (dashed line) peaks corresponding to the triply charged ions of $\mathrm{d}_{0^{-}}$ and $\mathrm{d}_{12}$-di-isopropyl modified peptide LFTGHPETLEK. This pair of di-isopropyl modified peptides, with an 
Table 1. The experimental ratios of four modified myoglobin tryptic peptides using the RABA approach

\begin{tabular}{|c|c|c|c|c|c|}
\hline \multirow[b]{2}{*}{ Peptides } & \multicolumn{5}{|c|}{ Expected ratio } \\
\hline & $1: 1$ & $2: 1$ & $5: 1$ & $10: 1$ & $20: 1$ \\
\hline & \multicolumn{5}{|c|}{ Experimental ratio } \\
\hline LFTGHPETLEK & $1.00: 1$ & $2.08: 1$ & 4.47:1 & $11.11: 1$ & 26.61:1 \\
\hline VEADIAGHGQEVLIR & $0.99: 1$ & $2.13: 1$ & $5.04: 1$ & $13.12: 1$ & $25.13: 1$ \\
\hline ALELFR & $0.97: 1$ & $2.31: 1$ & 5.33:1 & $13.86: 1$ & $29.40: 1$ \\
\hline HGTVVLTALGGILK & $0.94: 1$ & $2.31: 1$ & 4.97:1 & 13.20:1 & 31.92:1 \\
\hline Average experimental ratio & $0.98: 1$ & $2.21: 1$ & 4.95:1 & $12.82: 1$ & 28.27:1 \\
\hline RSD among peptides (\%) & 2.77 & 5.43 & 7.27 & 9.28 & 10.65 \\
\hline
\end{tabular}

isopropyl group at their $\mathrm{N}$-terminus and the $\mathrm{C}$-terminal lysine residue, is $12 \mathrm{Da}$ apart and largely co-eluted in the reverse phase HPLC with $\sim 8 \mathrm{~s}$ separation of retention time. The results are consistent with the literature that the HPLC separation of the light and heavy isotopic peptides increases with increasing content of deuterium. The mass spectrum was averaged over the peak elution of the peptide of interest in this study, thus the separation was less likely to interfere with the quantification accuracy. However, it increased the complexity of data analysis, which is yet to be automated. The HPLC separation of the deuterium labeled peptide can potentially be minimized by using ${ }^{13} \mathrm{C}$-labeled reagents as previously reported $[23,40,41]$. However, the ${ }^{13} \mathrm{C}$ labeled acetone $\left({ }^{13} \mathrm{C}_{3}\right.$-acetone) can only provide a maximal mass split of $3 \mathrm{Da}$ between the light and heavy isotopic peaks, which is less than ideal. The higher cost of ${ }^{13} \mathrm{C}$-labeled acetone would also undermine the costeffectiveness of the RABA approach afforded by inexpensive $\mathrm{d}_{6}$-acetone. In addition, a computational tool to automate the data analysis is yet to be developed to plot extracted ion chromatography of the peptide of interest, calculate the centroid intensity of the peptide peak averaged over the elution time, and correct the different elution time of the light and heavy isotopic peaks. Some published algorithms such as ASAPRatio [42], Xpress [17], and MSQuant can also be adapted for quantitative proteomics data analysis using the RABA approach.

Figure $3 \mathrm{c}$ is the average spectrum across the elution time of the peaks representing $d_{0^{-}}$and $d_{6}$-isopropyl modified peptide ALELFR. The ratio of the $\mathrm{d}_{0^{-}}$and $\mathrm{d}_{6}$-isopropyl modified peptides was calculated using the intensities of the corresponding light and heavy isotopic peaks. The experimental $\mathrm{d}_{0} / \mathrm{d}_{6}$ ratio of $0.97: 1$ agrees well with the expected ratio of 1:1.

Four pairs of $\mathrm{d}_{0^{-}}$and $\mathrm{d}_{6}$-isopropyl modified tryptic peptides were detected in all samples of different expected ratios. They were used to calculate the experimental ratios as described above and the results are summarized in Table 1. The experimental ratios of myoglobin were calculated using the average of four tryptic peptides and they agreed well with the expected ratios. The relative standard deviation (RSD) of the four peptides in each experiment was $\sim 10 \%$. The results demonstrate that the RABA approach can be used for quantitative analysis of proteins at the femtomole level in combination of nano-LC.

We subsequently applied this method to quantify two samples that consisted of three proteins BSA, myoglobin, and cytochrome $c$. The ratio of BSA, myoglobin and cytochrome $c$ in these two samples were 1:1, 2:1 and 10:1, respectively. After the RABA reaction with $\mathrm{d}_{0^{-}}$and $\mathrm{d}_{6}$-acetone and LC-MS/MS analysis, MASCOT database search identified 13,10 and $7 \mathrm{~d}_{0^{-}}$and $\mathrm{d}_{6^{-}}$ isopropyl modified tryptic peptides for BSA, myoglobin and cytochrome $c$, respectively. The sequence coverages were $54 \%, 88 \%$, and $69 \%$ for BSA, myoglobin, and cytochrome $c$, respectively. The experimental ratios were calculated using the intensities of the $d_{0^{-}}$and $\mathrm{d}_{6}$-isopropyl modified peptides and the average ratios of multiple peptides originated from the same protein are shown in Table 2. The data show that the experimentally determined ratios of three proteins are within $10 \%$ of the corresponding expected ratios. The RSD among the multiple peptides of the same protein was $\sim 15 \%$ or better.

Furthermore, we tested whether the RABA method can quantify tryptic peptides in the complex mixture. We mixed different amounts of BSA, myoglobin, and cytochrome $c$ with a fixed amount $(120 \mu \mathrm{g})$ of HEK293 cell lysate as described in the Experimental section. After trypsin digestion, the samples were subjected to RABA reaction using $\mathrm{d}_{0^{-}}$and $\mathrm{d}_{6}$-acetone and subsequently mixed and subjected to nano-LC-MS/MS analysis. Multiple peptides of BSA, myoglobin, and cytochrome $c$ in the complex background of thousand peptides derived from HEK293 cell lysate were identified by MASCOT search. The experimental ratios of

Table 2. The experimental ratios of BSA, myoglobin, and cytochrome $c$ determined by the RABA reaction with tryptic peptides

\begin{tabular}{lcccc}
\hline \multicolumn{1}{c}{ Protein } & Pairs of $\mathrm{d}_{0^{-}}$and $\mathrm{d}_{6}$ - modified peptides & Expected ratio & Average experimental ratio & RSD (\%) \\
\hline \hline BSA & 13 & $1: 1$ & $0.95: 1$ & 12.38 \\
Myoglobin & 10 & $2: 1$ & $1.90: 1$ & 9.44 \\
Cytochrome $c$ & 7 & $10: 1$ & $9.89: 1$ & 16.40 \\
\hline
\end{tabular}


Table 3. The experimental ratios of BSA, myoglobin, and cytochrome $c$ and other proteins in HEK293 cell lysate determined by the RABA approach

Experimental ratio (no. of peptides, RSD\%)

Target proteins

\begin{tabular}{|c|c|c|c|c|c|c|}
\hline \multirow[b]{2}{*}{ Sample } & \multirow[b]{2}{*}{ Expected ratio } & & \\
\hline & & BSA & Myoglobin & Cytochrome $c$ & Histone H1.4 & Actin \\
\hline$B: A$ & $1: 1$ & $0.93(6,5.16)$ & $0.95(6,5.79)$ & $0.91(2, \mathrm{~N} / \mathrm{A})$ & $0.98(4,8.16)$ & $1.03(2, \mathrm{~N} / \mathrm{A})$ \\
\hline C:A & $2: 1$ & $1.93(5,9.84)$ & $2.12(5,11.32)$ & $1.9(3,17.89)$ & $0.93(3,10.54)$ & $1.20(2, \mathrm{~N} / \mathrm{A})$ \\
\hline $\mathrm{D}: \mathrm{A}$ & $5: 1$ & $5.50(5,16.94)$ & $5.50(4,10.75)$ & $5.37(1, N / A)$ & $0.91(4,10.33)$ & $0.99(2, N / A)$ \\
\hline
\end{tabular}

BSA, myoglobin, and cytochrome $c$ as well as two HEK293 cellular proteins (histone H1.4 and actin) were determined and compared with the expected ratios as shown in Table 3. The ratios of BSA, myoglobin, and cytochrome $c$ were determined and were in excellent agreement with the expected ratios even they were mixed with HEK293 cell lysate. As a control, the expected ratio of all HEK293 cellular proteins is constant at 1:1 since a fixed amount of HEK293 cell lysate was used in all samples. The experimental ratios of histone H1.4 and actin were also consistent with the expected ratio in all experiments. The results demonstrate that the RABA method can be reliably applied to quantify proteins in a complex mixture.

It is particularly challenging to quantify low abundance proteins in a complex system. It is noted that the sensitivity of identifying and quantifying low abundance proteins using stable isotope labeling and LCMS/MS approach relies on at least three factors: (1) efficient isotope labeling reaction, (2) efficient LC separation, and (3) accuracy and sensitivity of mass spectrometry. In this paper introducing RABA approach as a novel stable isotope labeling strategy, we have focused on demonstrating the efficiency of the RABA reaction. However, it is critical to optimize the LCMS/MS platform available in individual laboratory to achieve accurate quantification of greater number of proteins including those with low abundance.

\section{Application of the RABA Method for Quantitative Analysis of Proteins in Transgenic Mouse Models of Amyotrophic Lateral Sclerosis}

We applied the RABA reaction with tryptic peptides to quantify proteins in mouse spinal cord homogenates from transgenic mouse models of Amyotrophic Lateral Sclerosis (ALS). The transgenic mice used in the study overexpress either wild-type (WT) or G93A mutant human copper-zinc-superoxide dismutase (SOD1) and are widely used as animal models of ALS [39, 43]. We identified 201 unique proteins (at least two unique peptides for each protein) using LC-MS/MS analysis of the tryptic digestion of spinal cord homogenates and quantified them using the RABA approach described above (Zhai et al., unpublished data). In this method development paper, we hereby present the quantitative results obtained with selected proteins as summarized in Table 4. In particular, we focus on the quantification of two proteins with high sequence homology in the transgenic mouse models: human and mouse SOD1 (Figure 4). In addition, we validated the quantitative results using the Western blotting technique as shown in Figure 5.

Figure $4 \mathrm{a}$ shows the sequence alignment of the transgenic human SOD1 and the endogenous mouse SOD1. Seven tryptic peptides of human SOD1 were identified, four of which are unique to human SOD1 (i.e., not present in mouse SOD1). The four unique human SOD1 peptides are shown in red in Figure 4a. Four peptides of mouse SOD1 were identified, one of which is unique to mouse SOD1 as shown in green in Figure $4 \mathrm{a}$. Three tryptic peptides that are common to human and mouse SOD1 are shown in yellow. The unique human SOD1 peptides were used to determine the ratio of the transgenic protein in two different transgenic mouse lines. Figure $4 \mathrm{~b}$ shows the average mass spectrum of all peptides eluted during 65.3 to 66.1 min and the $m / z 351.70$ peak is isopropyl modified peptide ADDLGK that is unique to human SOD1. The zoomed mass spectrum of the $\mathrm{d}_{0}$ - and $\mathrm{d}_{12}$-di-isopropyl modified forms of the peptide (doubly charged, $\mathrm{m} / \mathrm{z}$ 351.70 and $m / z$ 357.74) is shown in Figure 4c. The $\mathrm{d}_{0^{-}}$ and $\mathrm{d}_{12}$-di-isopropyl modified peptides were derived

Table 4. Quantification of transgenic human SOD1, endogenous mouse SOD1 and actin in wild-type (WT) and G93A mutant human SOD1 transgenic mouse models

\begin{tabular}{|c|c|c|c|}
\hline Protein & Unique Peptide & $\begin{array}{c}\text { Experimental } \\
\text { ratio } \\
\text { (WT/G93A) }\end{array}$ & $\begin{array}{c}\text { Average } \\
\text { (RSD\%) }\end{array}$ \\
\hline \multirow[t]{4}{*}{ hSOD1 } & ADDLGK & 1.92 & 2.15 (13.95) \\
\hline & VWGSIK & 2.10 & \\
\hline & ESNGPVK & 2.59 & \\
\hline & GDGPVQGIINFEQK & 2.00 & \\
\hline mSOD1 & VISLSGEHSIIGR & 1.05 & 1.05 (N/A) \\
\hline \multirow[t]{7}{*}{ Actin } & GILTLK & 1.19 & $1.00(12.70)$ \\
\hline & IIAPPER & 0.85 & \\
\hline & AGFAGDDAPR & 1.00 & \\
\hline & AVFPSIVGRPR & 0.83 & \\
\hline & DSYVGDEAOSK & 1.03 & \\
\hline & IWHHTFYNELR & 1.09 & \\
\hline & VAPEEHPVLLTEAPLNPK & 1.00 & \\
\hline
\end{tabular}




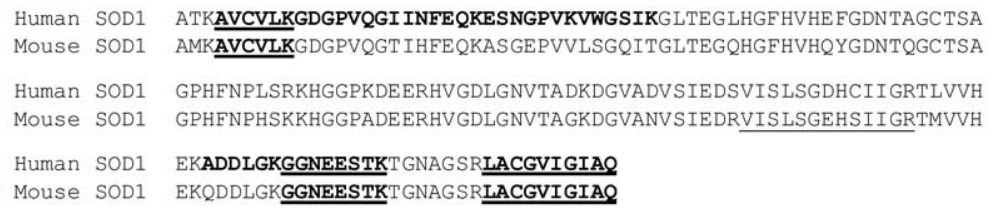

(a) Mouse SOD1 EKQDDLGKGGNEESTKT GNAGSRIACGVIGIAO

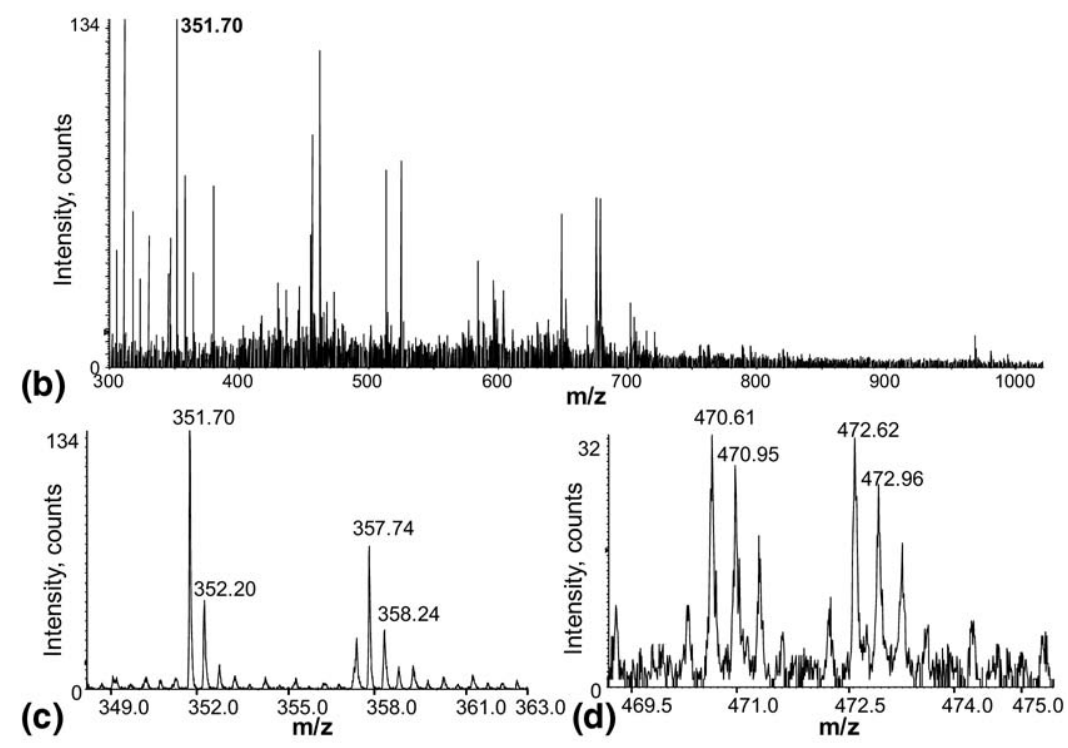

Figure 4. Quantitative analysis of mouse spinal crod proteins using the RABA approach. (a) Sequence alignment of the transgene human SOD1 and the endogenous mouse SOD1. The unique human SOD1 peptides identified in LC-MS/MS analysis are bold. The unique mouse SOD1 peptide is underlined. The peptides common to both human and mouse SOD1 are bold and underlined. (b) The average mass spectrum of the peptides eluted during 65.3-66.1 $\mathrm{min}$ in the LC-MS/MS analysis, including the human SOD1 unique peptide ADDGLK at $\mathrm{m} / \mathrm{z}$ 351.70. (c) The zoomed view of the mass spectrum of $\mathrm{d}_{0^{-}}$and $\mathrm{d}_{12}$-di-isopropyl modified peptide ADDLGK. (d) The zoomed view of the mass spectrum of $\mathrm{d}_{0^{-}}$and $\mathrm{d}_{6}$-isopropyl modified peptide VISLSGEHSIIGR that is unique to mouse SOD1.

from spinal cords of the WT and G93A mutant human SOD1 transgenic mouse models, respectively. The ratio of these two isotopic peaks was calculated to be 1.92 . The ratios of the four human SOD1 unique peptides were summarized in Table 4 . The average ratio of the four human SOD1 unique peptides was 2.15 with RSD of $13.95 \%$.

Figure $4 \mathrm{~d}$ shows the mass spectrum of the $\mathrm{d}_{0^{-}}$and $\mathrm{d}_{6}$-isopropyl modified mouse SOD1 unique peptide VISLSGEHSIIGR (triply charged, $m / z 470.61$ and 472.62). The ratio of the isotopic peaks was 1.05. Since this is the sole unique mouse SOD1 peptide identified, the ratio of endogenous mouse SOD1 between the two transgenic models was determined as 1.05. The result was consistent with the expectation that the endogenous SOD1 levels are constant in different transgenic lines. In addition, the ratio of the housekeeping protein actin between the two transgenic mouse models was calculated using seven tryptic peptides and the average ratio was 1.00 with RSD $12.70 \%$ (Table 4 ).

Furthermore, we validated the quantitative results obtained from the RABA method using the Western blotting technique. Figure 5 shows the Western blot of human SOD1 and it is evident that its expression level in WT SOD1 transgenic mouse was approximately two times higher than in the G93A mutant SOD1 transgenic mouse. The same film was exposed longer to detect the endogenous mouse SOD1 that was at a significantly lower level compared with the transgene human SOD1. The endogenous mouse SOD1 levels were approximately the same in the two transgenic mouse lines. The Western blotting of actin also showed unchanged expression between the two transgenic lines. The intensities of the human SOD1 band in WT and mutant SOD1 transgenic mice were quantified using the Kodak 1D software (version 3.6.1). After normalization with actin, the human SOD1 in WT SOD1 transgenic mouse was 1.89 times of that in the G93A mutant SOD1 transgenic mouse, which was consistent with the quantification result obtained using the RABA approach (average of 2.15 with RSD $13.95 \%$ ).

The above results demonstrate that the RABA method can be successfully applied to quantify proteins in complex samples. In addition, the RABA method can distinguish highly homologous proteins, such as human and mouse SOD1 in this study and can quantify them individually. The quantitative results obtained with this method are reliable and can be validated by independent techniques, such as Western blotting. The quantification of both human and mouse SOD1, whose expression levels are drastically different as evidenced by Western blot in Figure 5, supports that the RABA 

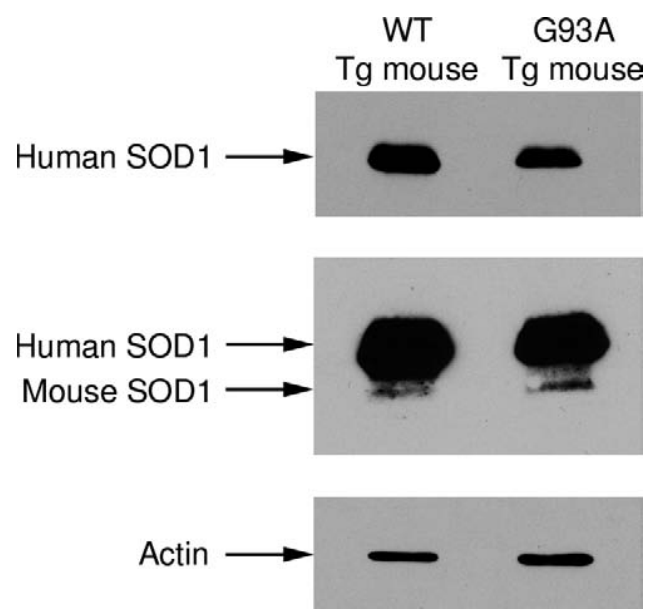

Figure 5. Western blotting validation of quantitative results obtained by the RABA approach. The level of human SOD1 in WT SOD1 transgenic mouse was approximately two time of that in G93A SOD1 transgenic mouse. The prolonged exposure detected mouse SOD1 and showed approximately equal expression between WT and SOD1 transgenic mouse models. The housekeeping protein actin was also unchanged between the two transgenic mouse models. All results are consistent with the quantitative analysis using the RABA approach and mass spectrometry.

approach can quantify low abundance proteins in a complex mixture.

\section{Conclusions}

We have developed a novel stable isotope labeling strategy for quantitative proteomic analysis. The RABA reaction can react with the primary amine groups at the $\mathrm{N}$-terminus and lysine residues stoichiometrically within a short period of time. When unlabeled $\left(\mathrm{d}_{0}\right)$ and deuterated $\left(\mathrm{d}_{6}\right)$ acetone are used, the reaction generates a pair of light and heavy isotope labeled peptides with mass separation of $6 \mathrm{Da}$ each reactive amine group in the peptide. The strategy is well suited for quantitative proteomic analysis because the $6 \mathrm{Da}$ mass separation can avoid the naturally occurring isotope envelop and the light and heavy isotope pairs largely co-elute in reverse phase HPLC. The RABA reaction has been utilized to label peptides. The utility of the approach was demonstrated using standard peptides, tryptic peptides from proteins as well as human cell lysate and transgenic mouse tissue homogenate. The results obtained in all experiments supported that the RABA method can be used to achieve reliable quantification of proteins levels at the femtomole range in complex samples. The advantages of the RABA approach include the relative simplicity of the reaction, the high yield to produce leveled peptides in a short period of time, and 6 Da mass separation between the light and heavy isotope labeled peptides. In addition, the ready availability of the inexpensive reagents makes this approach an appealing alternative for binary quantitative proteomic analysis. Similar approaches using ketones with long alkyl chains conceptually can be uti- lized for multiplex quantitative analysis, which is currently being investigated in our laboratory.

\section{Acknowledgments}

The authors thank Ping Shi and Rujuan Liu for technical assistance with cell culture and transgenic mice, Dr. Anna-Lena Ström for suggestions, and Dr. Jozsef Gal for critically reading the manuscript. This study was in part supported by NH grant R01NS49126 (to H.Z.). The authors acknowledge support from NIH/NCRR Center of Biomedical Research Excellence in the Molecular Basis of Human Disease (COBRE, P20RR020171) and NIH/NIEHS Superfund Basic Research Program (P42ES007380). The NIH Shared Instrumentation Grant S10RR023684 (to H.Z.) is acknowledged for purchasing the 4800 Plus MALDI-TOF-TOF mass spectrometer.

\section{Appendix A Supplementary Material}

Supplementary material associated with this article may be found in the online version at doi:10.1016/ j.jasms.2009.03.027.

\section{References}

1. Aebersold, R.; Mann, M. Mass spectrometry-based proteomics. Nature 2003, 422, 198-207.

2. Gorg, A.; Weiss, W.; Dunn, M. J. Current two-dimensional electrophoresis technology for proteomics. Proteomics 2004, 4, 3665-3685.

3. Gygi, S. P.; Rist, B.; Gerber, S. A.; Turecek, F.; Gelb, M. H.; Aebersold, R. Quantitative analysis of complex protein mixtures using isotope-coded affinity tags. Nat. Biotechnol. 1999, 17, 994-999.

4. Oda, Y.; Huang, K.; Cross, F. R.; Cowburn, D.; Chait, B. T. Accurate quantitation of protein expression and site-specific phosphorylation. Proc. Natl. Acad. Sci. U.S.A. 1999, 96, 6591-6596.

5. Ong, S. E.; Blagoev, B.; Kratchmarova, I.; Kristensen, D. B.; Steen, H.; Pandey, A.; Mann, M. Stable isotope labeling by amino acids in cell culture, SILAC, as a simple and accurate approach to expression proteomics. Mol. Cell. Proteom. 2002, 1, 376-386.

6. Pasa-Tolic, L.; Masselon, C.; Barry, R. C.; Shen, Y.; Smith, R. D. Proteomic analyses using an accurate mass and time tag strategy. Biotechniques 2004, 37, 621-624, 626-633, 636 passim.

7. Conrads, T. P.; Alving, K.; Veenstra, T. D.; Belov, M. E.; Anderson, G. A.; Anderson, D. J.; Lipton, M. S.; Pasa-Tolic, L.; Udseth, H. R.; Chrisler, W. B.; Thrall, B. D.; Smith, R. D. Quantitative analysis of bacterial and mammalian proteomes using a combination of cysteine affinity tags and 15N-metabolic labeling. Anal. Chem. 2001, 73, 2132-2139.

8. Washburn, M. P.; Ulaszek, R.; Deciu, C.; Schieltz, D. M.; Yates, J. R. III. Analysis of quantitative proteomic data generated via multidimensional protein identification technology. Anal. Chem. 2002, 74, $1650-$ 1657.

9. Dong, M. Q.; Venable, J. D.; Au, N.; Xu, T.; Park, S. K.; Cociorva, D.; Johnson, J. R.; Dillin, A.; Yates, J. R. III. Quantitative mass spectrometry identifies insulin signaling targets in C. elegans. Science 2007, 317, 660-663.

10. Everley, P. A.; Krijgsveld, J.; Zetter, B. R.; Gygi, S. P. Quantitative cancer proteomics: stable isotope labeling with amino acids in cell culture (SILAC) as a tool for prostate cancer research. Mol. Cell. Proteom. 2004, 3, 729-735.

11. Ibarrola, N.; Molina, H.; Iwahori, A.; Pandey, A. A novel proteomic approach for specific identification of tyrosine kinase substrates using [13C]tyrosine. J. Biol. Chem. 2004, 279, 15805-15813.

12. Zhu, H.; Hunter, T. C.; Pan, S.; Yau, P. M.; Bradbury, E. M.; Chen, X. Residue-specific mass signatures for the efficient detection of protein modifications by mass spectrometry. Anal Chem 2002, 74, 1687-1694.

13. Zhu, H.; Pan, S.; Gu, S.; Bradbury, E. M.; Chen, X. Amino acid residue specific stable isotope labeling for quantitative proteomics. Rapid Commun. Mass Spectrom. 2002, 16, 2115-2123.

14. Beardsley, R. L.; Karty, J. A.; Reilly, J. P. Enhancing the intensities of lysine-terminated tryptic peptide ions in matrix-assisted laser desorption/ionization mass spectrometry. Rapid Commun. Mass Spectrom. 2000, 14, 2147-2153.

15. Brancia, F. L.; Oliver, S. G.; Gaskell, S. J. Improved matrix-assisted laser desorption/ionization mass spectrometric analysis of tryptic hydrolysates of proteins following guanidination of lysine-containing peptides. Rapid Commun. Mass Spectrom. 2000, 14, 2070-2073.

16. Goodlett, D. R.; Keller, A.; Watts, J. D.; Newitt, R.; Yi, E. C.; Purvine, S.; Eng, J. K.; von Haller, P.; Aebersold, R.; Kolker, E. Differential stable 
isotope labeling of peptides for quantitation and de novo sequence derivation. Rapid Commun. Mass Spectrom. 2001, 15, 1214-1221.

17. Han, D. K.; Eng, J.; Zhou, H.; Aebersold, R. Quantitative profiling of differentiation-induced microsomal proteins using isotope-coded affinity tags and mass spectrometry. Nat. Biotechnol. 2001, 19, 946-951.

18. Hsu, J. L.; Huang, S. Y.; Chow, N. H.; Chen, S. H. Stable-isotope dimethyl labeling for quantitative proteomics. Anal. Chem. 2003, 75, 6843-6852.

19. Ji, C.; Li, L. Quantitative proteome analysis using differential stable isotopic labeling and microbore LC-MALDI MS and MS/MS. J. Proteome Res. 2005, 4, 734-742.

20. Munchbach, M.; Quadroni, M.; Miotto, G.; James, P. Quantitation and facilitated de novo sequencing of proteins by isotopic N-terminal labeling of peptides with a fragmentation-directing moiety. Anal. Chem. 2000, 72, 4047-4057.

21. Ranish, J. A.; Yi, E. C.; Leslie, D. M.; Purvine, S. O.; Goodlett, D. R.; Eng, J.; Aebersold, R. The study of macromolecular complexes by quantitative proteomics. Nat. Genet. 2003, 33, 349-355.

22. Zhang, X.: Jin, Q. K. Carr, S. A.; Annan, R. S. N-Terminal peptide labeling strategy for incorporation of isotopic tags: A method for the determination of site-specific absolute phosphorylation stoichiometry. Rapid Commun. Mass Spectrom. 2002, 16, 2325-2332.

23. Boersema, P. J.; Aye, T. T.; van Veen, T. A.; Heck, A. J.; Mohammed, S. Triplex protein quantification based on stable isotope labeling by peptide dimethylation applied to cell and tissue lysates. Proteomics 2008, $8,4624-4632$

24. Che, F. Y.; Fricker, L. D. Quantitation of neuropeptides in Cpe(fat)/ Cpe(fat) mice using differential isotopic tags and mass spectrometry. Anal. Chem. 2002, 74, 3190-3198.

25. Geng, M.; Ji, J.; Regnier, F. E. Signature-peptide approach to detecting proteins in complex mixtures. J. Chromatogr. A 2000, 870, 295-313.

26. Schmidt, A.; Kellermann, J.; Lottspeich, F. A novel strategy for quantitative proteomics using isotope-coded protein labels. Proteomics 2005, 5 , $4-15$.

27. Mirgorodskaya, O. A.; Kozmin, Y. P.; Titov, M. I.; Korner, R.; Sonksen, C. P.; Roepstorff, P. Quantitation of peptides and proteins by matrixassisted laser desorption/ionization mass spectrometry using (18)Olabeled internal standards. Rapid Commun. Mass Spectrom. 2000, 14, 1226-1232.

28. Yao, X.; Freas, A.; Ramirez, J.; Demirev, P. A.; Fenselau, C. Proteolytic 180 labeling for comparative proteomics: model studies with two serotypes of adenovirus. Anal. Chem. 2001, 73, 2836-2842.

29. Ross, P. L.; Huang, Y. N.; Marchese, J. N.; Williamson, B.; Parker, K.; Hattan, S.; Khainovski, N.; Pillai, S.; Dey, S.; Daniels, S.; Purkayastha, S.; Juhasz, P.; Martin, S.; Bartlet-Jones, M.; He, F.; Jacobson, A.; Pappin, D. J. Multiplexed protein quantitation in Saccharomyces cerevisiae using amine-reactive isobaric tagging reagents. Mol. Cell. Proteom. 2004, 3, 1154-1169.
30. Aggarwal, K.; Choe, L. H.; Lee, K. H. Quantitative analysis of protein expression using amine-specific isobaric tags in Escherichia coli cells expressing rhsA elements. Proteomics 2005, 5, 2297-2308.

31. DeSouza, L.; Diehl, G.; Rodrigues, M. J.; Guo, J.; Romaschin, A. D. Colgan, T. J.; Siu, K. W. Search for cancer markers from endometrial tissues using differentially labeled tags iTRAQ and cICAT with multidimensional liquid chromatography and tandem mass spectrometry. I. Proteome Res. 2005, 4, 377-386.

32. Li, K.; Hornshaw, M. P.; van Minnen, J.; Smalla, K. H.; Gundelfinger E. D.; Smit, A. B. Organelle proteomics of rat synaptic proteins: Correlation-profiling by isotope-coded affinity tagging in conjunction with liquid chromatography-tandem mass spectrometry to reveal postsynaptic density specific proteins. J. Proteome Res. 2005, 4, 725-733.

33. Wiese, S.; Reidegeld, K. A.; Meyer, H. E.; Warscheid, B. Protein labeling by iTRAQ: A new tool for quantitative mass spectrometry in proteome research. Proteomics 2007, 7, 340-350.

34. Choe, L.; D'Ascenzo, M.; Relkin, N. R.; Pappin, D.; Ross, P.; Williamson, B.; Guertin, S.; Pribil, P.; Lee, K. H. 8-Plex quantitation of changes in cerebrospinal fluid protein expression in subjects undergoing intravenous immunoglobulin treatment for Alzheimer's disease. Proteomics 2007, 7, 3651-3660.

35. Phanstiel, D.; Unwin, R.; McAlister, G. C.; Coon, J. J. Peptide quantification using 8-Plex isobaric tags and electron transfer dissociation tandem mass spectrometry. Anal. Chem. 2009, 81, 1693-1698.

36. Fretheim, K.; Iwai, S.; Feeney, R. E. Extensive modification of protein amino groups by reductive addition of different sized substituents. Int. J. Pept. Protein Res. 1979, 14, 451-456.

37. Lundblad, R. L. Chemical Reagents for Protein Modification, 3rd ed.; CRC Press: Boca Raton, FL, 2005; p. 51-52

38. Gal, J.; Strom, A. L.; Kilty, R.; Zhang, F.; Zhu, H. p62 Accumulates and enhances aggregate formation in model systems of familial amyotrophic lateral sclerosis. J. Biol. Chem. 2007, 282, 11068-11077.

39. Zhang, F.; Strom, A. L.; Fukada, K.; Lee, S.; Hayward, L. J.; Zhu, H. Interaction between familial amyotrophic lateral sclerosis (ALS)-linked SOD1 mutants and the dynein complex. J. Biol. Chem. 2007, 282, 16691-16699.

40. Zhang, R.; Sioma, C. S.; Thompson, R. A.; Xiong, L.; Regnier, F. E. Controlling deuterium isotope effects in comparative proteomics. Anal. Chem. 2002, 74, 3662-3669.

41. Faca, V.; Coram, M.; Phanstiel, D.; Glukhova, V.; Zhang, Q.; Fitzgibbon, M.; McIntosh, M.; Hanash, S. Quantitative analysis of acrylamide labeled serum proteins by LC-MS/MS. J. Proteome Res. 2006, 5, 2009 2018.

42. Li, X. J.; Zhang, H.; Ranish, J. A.; Aebersold, R. Automated statistical analysis of protein abundance ratios from data generated by stableisotope dilution and tandem mass spectrometry. Anal. Chem. 2003, 75, 6648-6657.

43. Gurney, M. E. Transgenic mouse model of amyotrophic lateral sclerosis. N. Engl. J. Med. 1994, 331, 1721-1722. 